\title{
SCIAMACHY lunar occultation water vapor measurements: retrieval and validation results
}

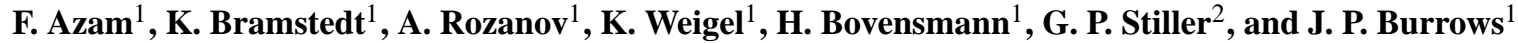 \\ ${ }^{1}$ Institute of Environmental Physics - IUP, University of Bremen, Bremen, Germany \\ ${ }^{2}$ Institute for Meteorology and Climate Research - IMK, Karlsruhe Institute of Technology - KIT, Karlsruhe, Germany \\ Correspondence to: F. Azam (faiza@iup.physik.uni-bremen.de)
}

Received: 31 October 2011 - Published in Atmos. Meas. Tech. Discuss.: 3 February 2012

Revised: 31 August 2012 - Accepted: 3 September 2012 - Published: 24 October 2012

\begin{abstract}
SCIAMACHY (SCanning Imaging Absorption spectroMeter for Atmospheric CHartographY) lunar occultation measurements have been used to derive vertical profiles of stratospheric water vapor for the Southern Hemisphere in the near infrared (NIR) spectral range of 1350-1420 nm. The focus of this study is to present the retrieval methodology including the sensitivity studies and optimizations for the implementation of the radiative transfer model on SCIAMACHY lunar occultation measurements. The study also includes the validation of the data product with the collocated measurements from two satellite occultation instruments and two instruments measuring in limb geometry. The SCIAMACHY lunar occultation water vapor measurement comparisons with the ACE-FTS (Atmospheric Chemistry Experiment Fourier Transform Spectrometer) instrument have shown an agreement of $5 \%$ on the average that is well within the reported biases of ACE in the stratosphere. The comparisons with HALOE (Halogen Occultation Experiment) have also shown good results where the agreement between the instruments is within $5 \%$. The validations of the lunar occultation water vapor measurements with MLS (Microwave Limb Sounder) instrument are exceptionally good, varying between 1.5 to around $4 \%$. The validations with MIPAS (Michelson Interferometer for Passive Atmospheric Sounding) are in the range of $10 \%$. A validated dataset of water vapor vertical distributions from SCIAMACHY lunar occultation measurements is expected to facilitate the understanding of physical and chemical processes in the southern midlatitudes and the dynamical processes related to the polar vortex.
\end{abstract}

\section{Introduction}

SCIAMACHY (SCanning Imaging Absorption spectroMeter for Atmospheric CHartographY) (Burrows et al., 1995) is a moderate resolution 8-channel grating spectrometer on-board Envisat, launched in 2002. The instrument measures solar irradiances and the earthshine radiances from the UV to the NIR (near infrared) $(240-2380 \mathrm{~nm}) \mathrm{spec}$ tral region in nadir, limb and solar/lunar occultation geometry. SCIAMACHY is dedicated to improving our knowledge in atmospheric composition and global atmospheric change (Bovensmann et al., 1999). Since the launch of its host satellite, the instrument has provided total columns as well as vertical profiles of atmospheric parameters relevant to ozone chemistry, air pollution and global climate change issues, from the troposphere up to the mesosphere (Gottwald and Bovensmann, 2011).

SCIAMACHY lunar occultation measurements have provided valuable datasets of atmospheric species, as ozone, nitrate radical and nitrogen dioxide (Amekudzi et al., 2005, 2009), which have been used for physical and chemical interpretations and analysis.

Water vapor is the most abundant and highly variable green house gas in the Earth's atmosphere. Depending on the latitude and altitude, the distribution of water vapor directly affects the physics, chemistry, dynamics and the radiation in the atmosphere (Solomon et al., 2010). Owing to its longer chemical lifetime with respect to the timescale of the stratospheric dynamical processes, water vapor is used as an excellent tracer of atmospheric circulations and waves, etc. (Pan et al., 2007). The primary source of water vapor in the lowermost stratosphere is the adiabatic injection across the tropical 
tropopause. However, this has to pass through the cold trap of the temperature minimum at the tropopause region; above this region the oxidation of methane and other hydrocarbons release hydrogen containing free radicals with $\mathrm{H}_{2} \mathrm{O}$ being formed by the reaction with $\mathrm{OH}$. Thus, very low water vapor amounts are found in the tropical lower stratosphere due to the air ascending through the cold tropical tropopause region with an annual average of around $3.8 \mathrm{ppmv}$ (Dessler and Kim, 1999). In the upper stratosphere, methane oxidation is the dominant local stratospheric water vapor source (Abbas et al., 1996; Michelsen et al., 2000), and the relationship between stratospheric methane and water vapor has been demonstrated in previous studies (Gurlit et al., 2005). Higher water vapor mixing ratios are observed with increasing altitude reaching around $7 \mathrm{ppmv}$ near the stratopause (Pan et al., 2002). The large scale general circulation across the hemispheres brings the moist air into the polar region where it descends inside the polar vortex. In the polar stratosphere, the water vapor amounts remain high with the exception of the dehydration events in the polar lower stratosphere due to the formation of polar stratospheric clouds (PSCs). Inside the polar vortex, the water vapor amounts directly influence the ozone depletion by controlling the formation temperatures, the size of the polar stratospheric clouds (KirkDavidoff et al., 1999; Kirk-Davidoff and Lamarque, 2008), and the polar vortex temperatures.

SCIAMACHY's measurements in the occultation mode are self calibrating and have high accuracy. This feature also makes them well suited for the trend analysis. The measurements give localized coverage where the vertical profiles of stratospheric constituents are retrieved with a vertical resolution of $3-4 \mathrm{~km}$.

\section{SCIAMACHY lunar occultation}

SCIAMACHY lunar occultation measurements are carried out over the southern high latitudes between $59-89^{\circ} \mathrm{S}$ during local nighttime, and the measurements from 2002 to 2010 are used in this study. The latitudinal constraint is due to the sun synchronous orbit of Envisat and the placement of the instrument on the satellite. The SCIAMACHY's field of view (FOV) in lunar occultation mode is $0.045^{\circ}(2.5 \mathrm{~km})$ in the vertical direction and $1.8^{\circ}$ in the horizontal direction. The apparent diameter of the moon is between $0.49^{\circ}$ and $0.57^{\circ}$ in the horizontal direction, which is within the instrument's FOV. The properties of moonrise in SCIAMACHY's FOV are determined by the orientation of the lunar orbital plane with respect to Envisat's orbital plane and the ecliptic. Each measurement starts when the moon rises above a tangent height altitude of around $17.2 \mathrm{~km}$. Below this altitude, the lunar signal is rapidly decreasing. The scanner follows the predicted movement of the moon for $16 \mathrm{~s}$, then the moon follower device (MFD) takes over and adjusts the scanner to the brightest point of the moon. The switch is at an altitude of about $65 \mathrm{~km}$. Above $100 \mathrm{~km}$, the measurements are performed for calibration purposes and to calculate transmission. The moonrise is observed when the phase is $>0.5$ in the instrument's FOV with solar zenith angle (SZA) $>94^{\circ}$. The measurements end shortly after the full moon.

In the southern polar region, the polar night lasts from April till September. The winter season spans from June to September. The months of July, August and September endure the coldest temperatures. During this period, the heterogeneous chemistry on the surface of PSCs kicks off the formation of the ozone hole. As originally proposed, SCIAMACHY comprised two instruments for limb and nadir. As a result of cost reduction imposed by the space agencies, the instrumentation aboard Envisat in its sun synchronous orbit comprises a single instrument, undertaking solar occultation in the Northern Hemisphere, alternate but matched limb and nadir during an orbit, and lunar occultation in the Southern Hemisphere. On the average, the yearly SCIAMACHY lunar occultation measurements extend from November to June owing to the limitations described above. Occasionally there are a few measurements in October. The pattern implies that the atmospheric species participating in the heterogeneous chemistry and chemical processes at high latitudes cannot be observed by these measurements. In the southern polar stratosphere, the formation of the vortex begins to spin up in March, and, as a result of momentum transport to high latitudes, it breaks down typically in November or December. The quantitative analysis of water vapor distributions and variability in the polar stratosphere provides a perspective into the evolution and the break down of the polar vortex. The strong relationship between water vapor and the upper atmospheric dynamics has been established in various studies (Russell et al., 1993a; Lahoz et al., 1993, 1996). The retrieval of stratospheric water vapor from SCIAMACHY lunar occultation measurements yields some unique insight into the dynamics of the stratosphere and provides the motivation behind the study.

\section{Solar zenith angle and the moon phase distribution for the lunar occultation measurements}

The geographical distribution of SCIAMACHY lunar occultation measurements is sparse, as can be seen in the example in Fig. 1 which shows the tangent points for the year 2010. Figure 2 shows the latitudinal distribution time series for the years 2003-2010. As clearly seen, there is a large latitudinal variation within a month and over a year. This is due to the fact that the latitude of the sub-satellite point changes considerably at the moonrise within a month. This feature makes the measurements suitable for studying the southern polar atmosphere at various latitudes during a year. On the average, each year the measurement span is $\sim 59-89^{\circ} \mathrm{S}$ from January till June. In November and December, the measurements are limited to $60-70^{\circ} \mathrm{S}$. 


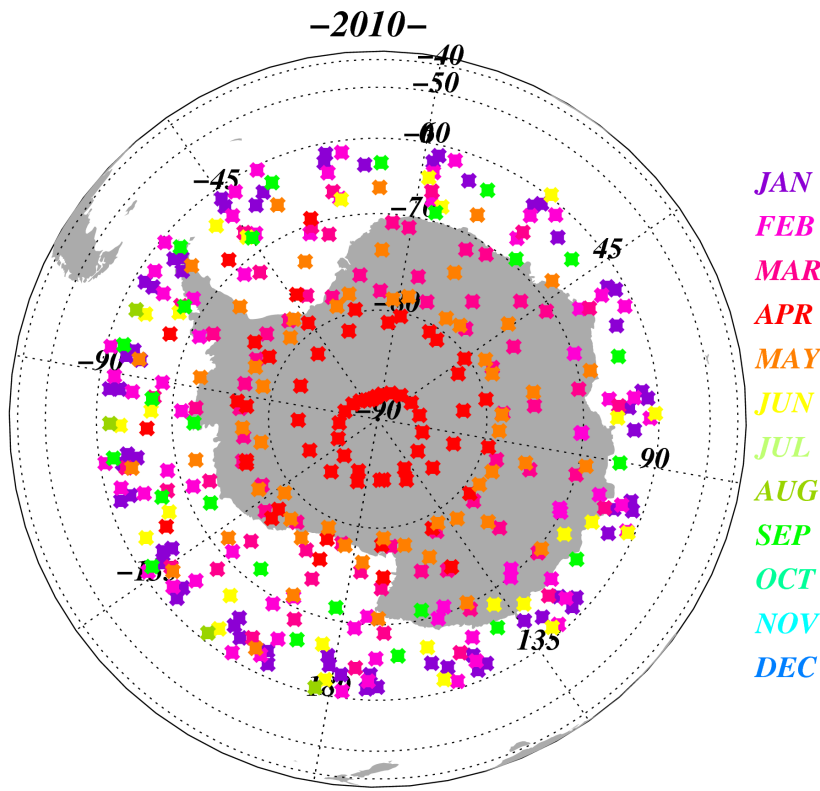

Fig. 1. SCIAMACHY lunar occultation tangent points in 2010; the latitudes vary within $59^{\circ} \mathrm{S}-89^{\circ} \mathrm{S}$.

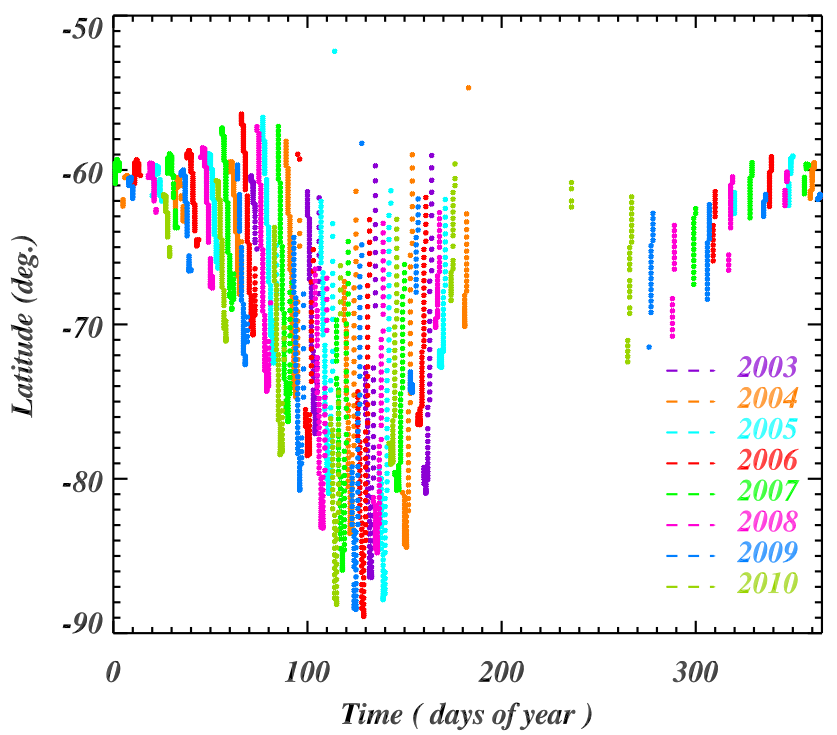

Fig. 2. SCIAMACHY lunar occultation latitudinal distribution for the years 2003-2010; each year the latitudes vary considerably between $59^{\circ} \mathrm{S}-89^{\circ} \mathrm{S}$.

The yearly time series of solar zenith angle (SZA) and moon phase for SCIAMACHY lunar occultation measurements are shown in Figs. 3 and 4, respectively. The SZA variation for each year is between $94^{\circ}$ and $115^{\circ}$, with the highest values observed around April. The observed moon phase values vary around $0.5-0.99$. The assignment of phase is as follows: For the half moon, the phase is 0.5 , and so on. The smaller the SZA value, the higher is the influence of the sunlight scattered due to the Earth's atmosphere, whereas

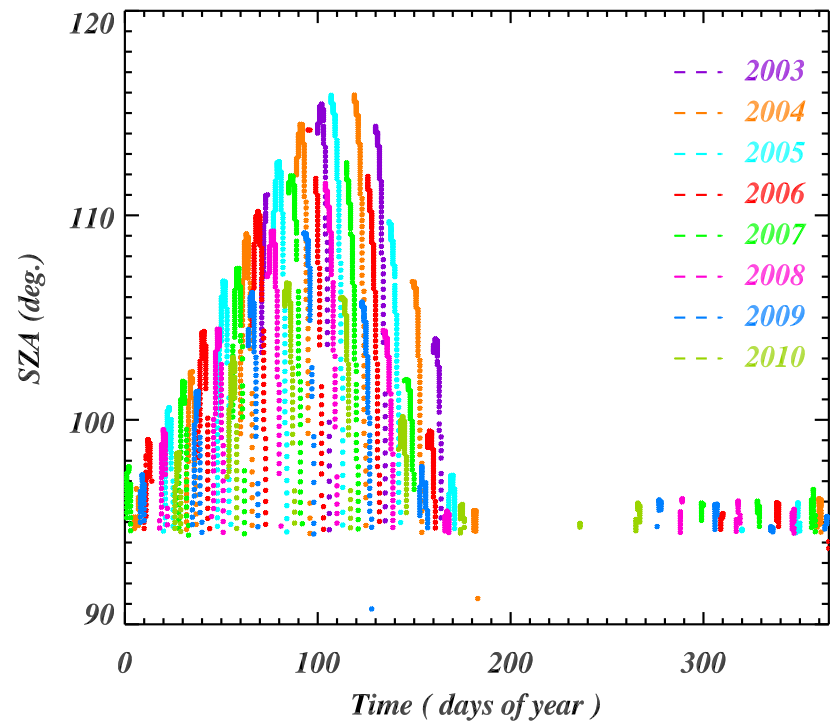

Fig. 3. SCIAMACHY lunar occultation SZA distribution for the years 2003-2010; each year the SZA span is within $94^{\circ}$ and $115^{\circ}$.

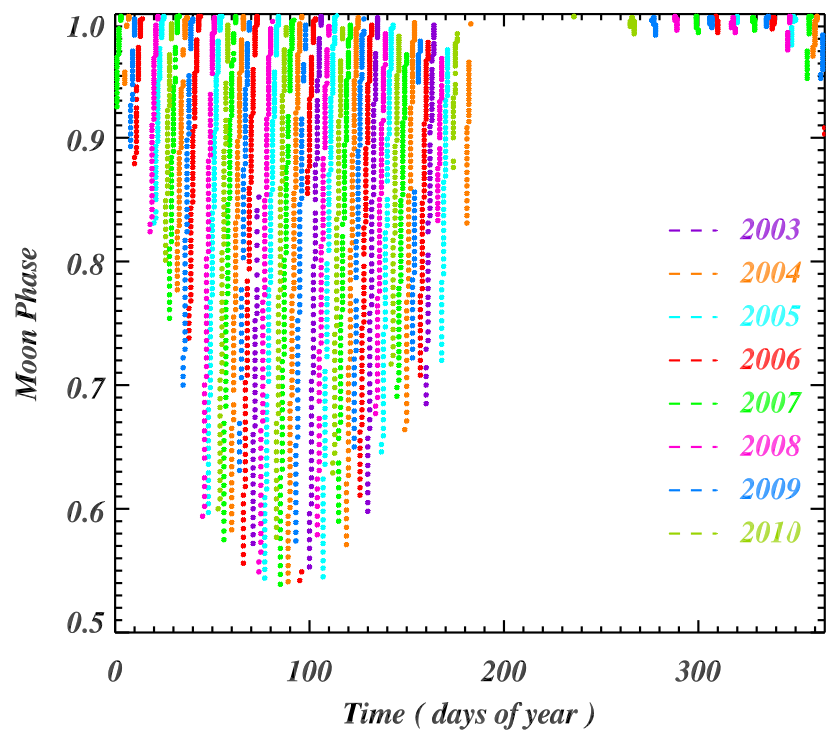

Fig. 4. SCIAMACHY lunar occultation moon phase distribution for the years 2003-2010; the observed moon phase values vary around $0.5-0.99$.

for moon phase, the higher values signify a strong signal. The quality of the SCIAMACHY lunar occultation spectral signal is essentially determined by the values of the SZA and the moon phase. The quality criteria thus implied were the selection of measurements with moon phase $\geqslant 0.75$ and $\mathrm{SZA} \geqslant 96^{\circ}$. On the average, the usable SCIAMACHY lunar occultation measurements are 6 days a month and 68 months in a year. 


\section{Retrieval theory}

This section explains the retrieval method implied on the SCIAMACHY lunar occultation measurements. The scheme is explained in depth in Amekudzi (2005) and the references therein, and will be described here in brief with emphasis on the theory that is essential to understand the contents of Sect. 5. The basic equation to be solved is a nonlinear, illposed inverse problem (Rodgers, 2000),

$\boldsymbol{y}=F(\boldsymbol{x}, \boldsymbol{b})+\boldsymbol{\varepsilon}$,

relating the measurement vector $\boldsymbol{y}$, i.e. the measured lunar spectrum, by a forward model $F$. The state vector $x$ represents the water vapor vertical profile to be estimated. The forward model $F$ accounts for the physics of the measurement including the instrument characterization. The vector $\boldsymbol{b}$ includes the model parameters such as line strength, pressure broadening, temperature etc. The symbol $\varepsilon$ represents errors of all kinds. Equation (1) is linearized with respect to a reference state signifying the first estimate of the true atmospheric state, termed as the a priori $\boldsymbol{x}_{\mathrm{a}}$. The a priori is introduced by a climatology. The linearization is performed by using the Taylor series expansion and neglecting its higher terms:

$\boldsymbol{y}=F\left(\boldsymbol{x}_{\mathrm{a}}\right)+\left.\frac{\partial F(\boldsymbol{x})}{\partial \boldsymbol{x}}\right|_{\boldsymbol{x}_{\mathrm{a}}}\left(\boldsymbol{x}-\boldsymbol{x}_{\mathrm{a}}\right)+\boldsymbol{\varepsilon}$,

where the differential on the right hand side is the weighting function matrix taking into account the sensitivity of the measurement to the true profile. It is denoted by $\mathbf{K}, \mathbf{K} \approx \partial \boldsymbol{y} / \partial \boldsymbol{x}$. Thus

$\hat{\boldsymbol{y}}=\boldsymbol{y}-\boldsymbol{y}_{\mathrm{a}}=\mathbf{K} \hat{\boldsymbol{x}}+\boldsymbol{\varepsilon}=\mathbf{K}\left(\boldsymbol{x}-\boldsymbol{x}_{\mathrm{a}}\right)+\boldsymbol{\varepsilon}$

relates the measurement state vector $\hat{\boldsymbol{y}}$ and the model state vector $\hat{\boldsymbol{x}} ; \boldsymbol{y}_{\mathrm{a}}$ is the simulated a priori spectra. The retrieval solution is obtained by applying the optimal estimation and using the Newton iterative scheme as described in Rodgers (2000), which, for an $(i+1)$-th step, results in

$$
\begin{aligned}
\boldsymbol{x}_{i+1}= & \boldsymbol{x}_{\mathrm{a}}+\left(\mathbf{K}_{i}^{T} \mathbf{S}_{y}^{-1} \mathbf{K}_{i}+\mathbf{S}_{\mathrm{a}}^{-1}\right)^{-1} \\
& \mathbf{K}_{i}^{T} \mathbf{S}_{y}^{-1}\left(\boldsymbol{y}-\boldsymbol{y}_{i}+\mathbf{K}_{i}\left(\boldsymbol{x}_{i}-\boldsymbol{x}_{\mathrm{a}}\right)\right),
\end{aligned}
$$

with $\mathbf{S}_{\mathrm{a}}$ as the constraint matrix for the state vector called a priori covariance matrix, reflecting uncertainties of the a priori height profiles, and $\mathbf{S}_{y}$ as the measurement error covariance matrix representing the measurement noise for every measurement height and wavelength. In this study, $100 \%$ a priori covariance is assumed. In Eq. (4),

$\mathbf{D}_{i}=\left(\mathbf{K}_{i}^{T} \mathbf{S}_{y}^{-1} \mathbf{K}_{i}+\mathbf{S}_{\mathrm{a}}^{-1}\right)^{-1} \mathbf{K}_{i}^{T} \mathbf{S}_{y}^{-1}$

is the contribution function representing the sensitivity of the retrieval to the measurement, implying $\mathbf{D} \approx \partial \hat{\boldsymbol{x}} / \partial \boldsymbol{y}$. The convergence to terminate the iterations is achieved when the measurement residuals $\boldsymbol{y}_{i}-\boldsymbol{y}$ are sufficiently small or the retrieved profile does not change anymore during the iterations.

Inverse problems in general are sensitive to small perturbations that may introduce unrealistic features. In our study, the inversion was stabilized by using an optimization approach which suppresses the additive noise. A regularization term called the Tikhonov regularization (Tikhonov, 1963; Tikhonov and Arsenin, 1997) was introduced in the retrieval solution by extending the inverse of the a priori covariance matrix by a Tikhonov matrix as

$\mathbf{S}_{\mathrm{a}}^{-1} \longrightarrow \mathbf{S}_{\mathrm{a}}^{-1}+\mathbf{S}_{t}^{T} \mathbf{S}_{t}$.

This constrains the smoothness of the retrieved profile $\hat{\boldsymbol{x}}$, contributing to the desired state of the retrieved atmospheric parameter. In Eq. (6), $\mathbf{S}_{t}$ is the first order derivative matrix weighted by an appropriate parameter termed the Tikhonov parameter. An appropriate value of the Tikhonov parameter has to be selected, as will be shown in Sect. 5.4.4, minimizing the loss of information.

The retrieval solution covariance matrix (smoothing error and retrieval noise) corresponding to Eq. (4) is given by

$\mathbf{S}=\left(\mathbf{K}_{i}^{T} \mathbf{S}_{y}^{-1} \mathbf{K}_{i}+\mathbf{S}_{\mathrm{a}}^{-1}\right)^{-1}$

The diagonal elements of $\mathbf{S}$ are the covariances of the retrieved water vapor profiles and are the indicators of the theoretical precision of the retrieval.

\section{Water vapor retrieval}

\subsection{Data}

The data used for the retrieval was the SCIAMACHY lunar occultation level $1 \mathrm{~b}(11 \mathrm{~b})$ data provided by ESA. The $11 \mathrm{~b}$ data contain the measured raw spectra and all information necessary for calibration. In our study the data versions 6.03 and 7.0 were used, completing the period of 2002-2010 to derive the vertical profiles of stratospheric water vapor from $\sim 17-50 \mathrm{~km}$ in the NIR spectral region. The data version 6.03 covers 2002-2009. Starting in October 2009, the processing switched to version 7.0; reprocessing of the earlier period was not complete at the time of this study. Version $7.0 \mathrm{in}$ cludes improvements for some of the calilbration data. However, for the wavelength region and the calibration steps applied for this study (Sect. 5.3), the calibration data are the same in both data versions, therefore the switch in the data version has no impact.

\subsection{Wavelength window}

The wavelength window available in the NIR region for the retrieval of SCIAMACHY lunar occultation water vapor profiles was $1350-1450 \mathrm{~nm}$ in channel 6 of the spectrometer. Figure 5 shows a spectral fit plot for this window. The green 


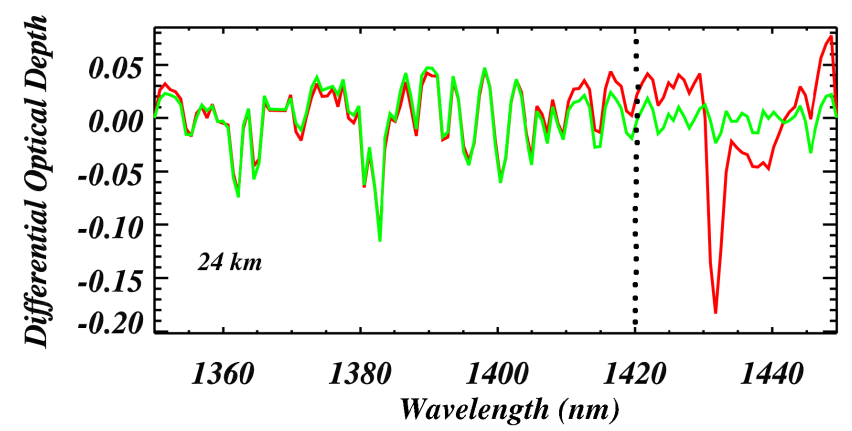

Fig. 5. Spectral plot for the wavelength window $1350-1450 \mathrm{~nm}$ and $24 \mathrm{~km}$ tangent height: Red line is the measured water vapor differential absorption spectrum. Green line is the corresponding modelled differential optical depth. A strong $\mathrm{CO}_{2}$ absorption line is present around $1430 \mathrm{~nm}$. Wavelength section 1350-1420 nm was selected for the retrieval (Measurement: 13 March 2006, orbit $=21085, \mathrm{SZA}=109.137$, moon phase $=0.93)$.

line is the modelled differential optical depth, and the red line represents the measured differential spectrum of water vapor. The attributes of the differential optical depth spectra and their calculation are described in Sect. 5.4.1. The spectral window $1350-1450 \mathrm{~nm}$ contains a strong absorption by $\mathrm{CO}_{2}$ around $1430 \mathrm{~nm}$. To obviate any complexity arising from the exponential sum fitting of transmission (ESFT) coefficients approximation radiative transfer method (see Sect. 5.4) in handling two absorbers in the same window, the wavelength section $1350-1420 \mathrm{~nm}$ was selected as the extraction and retrieval wavelength window. A good fit was observed for $1350-1420 \mathrm{~nm}$. Figure 6 shows the residual plot for the selected window, associated to Fig. 5, signifying the difference between the measured and the simulated differential spectra. As can be seen, the residuals are of the order of $0.5 \%$, which is within the signal to noise ratio.

\subsection{Lunar spectrum extraction}

The raw lunar radiance spectra are calibrated for offsets such as nonlinearlity, straylight and dark current correction. In addition, the spectral calibration is performed. Proceeding these corrections and calibration, the lunar spectrum $\boldsymbol{I}_{j}\left(\boldsymbol{h}_{j}, \lambda\right)$ or simply $\boldsymbol{I}_{j}(\lambda)$ was extracted for 13 tangent heights $\boldsymbol{h}_{j}$, between $17-50 \mathrm{~km}$, selecting the 14 th at $120 \mathrm{~km}$, which was the reference spectrum $\boldsymbol{I}_{\text {ref }}(\lambda)$. The ratio of the lunar spectrum to the reference is the transmission spectrum used. The NIR detectors of SCIAMACHY contain some bad pixels due to the lattice mismatch between the substrate and the light detecting material of the detector. The bad pixels may result in disconnected pixels, different detected pixels for the same intensity, excessive noise or a very high leakage current. Two bad pixels were identified in the wavelength region $1350-1420 \mathrm{~nm}$ and excluded.

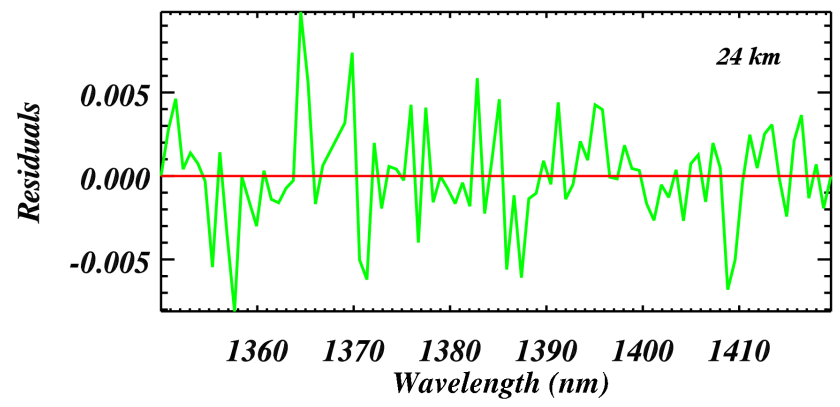

Fig. 6. Residual plot for the selected wavelength window 1350$1420 \mathrm{~nm}$ (corresponds to the same measurement as for Fig. 5): The residuals signify the difference between the measured and the simulated differential transmitted spectra. The residuals are about $0.5 \%$.

\subsection{Retrieval methodology, sensitivity studies and optimizations}

A robust and efficient inversion scheme and retrieval algorithm, SCIATRAN, is implemented on SCIAMACHY measurements for the retrieval of atmospheric parameters from the ultraviolet to near infrared region. This algorithm was developed at Institute of Environmental Physics/Remote Sensing, University of Bremen (Rozanov, 2001), as an extension of UV-Visible GOMETRAN radiative transfer model (Rozanov et al., 1997). The vertical profiles of water vapor from SCIAMACHY lunar occultation observations were retrieved using SCIATRAN version 3.0. In the framework of an optimal estimation approach, SCIATRAN is applied as a forward model, i.e. a radiative transfer model (RTM), and a retrieval code, i.e. the inverse part which fits the results from the former to the real measurements. The spectral absorption line features were treated by using the exponential sum fitting of transmission coefficients method (ESFT) (Sect. 5.4.3), employing correlated- $k$ distribution instead of the line by line (LBL) treatment of the line absorbers. The retrieval methodology for the ESFT approach is illustrated in Fig. 7.

\subsubsection{Forward model/radiative transfer part}

The forward model or the radiative transfer part takes input parameters such as initial water vapor profile, i.e. the a priori, viewing angles, pressure and temperature distributions, cross sections and instrument slit function. For the current retrieval, the initial guess and a priori along with the temperature and pressure were taken from the US Standard Atmosphere climatology (NASA, 1976). The ESFT database is calculated, at the given temperature and pressure, from the HITRAN database (Rothman et al., 2009) that contains individual absorption lines. The SCIATRAN forward model performs two functions, namely, simulating the transport of radiation through the atmosphere and computing the weighting functions. 


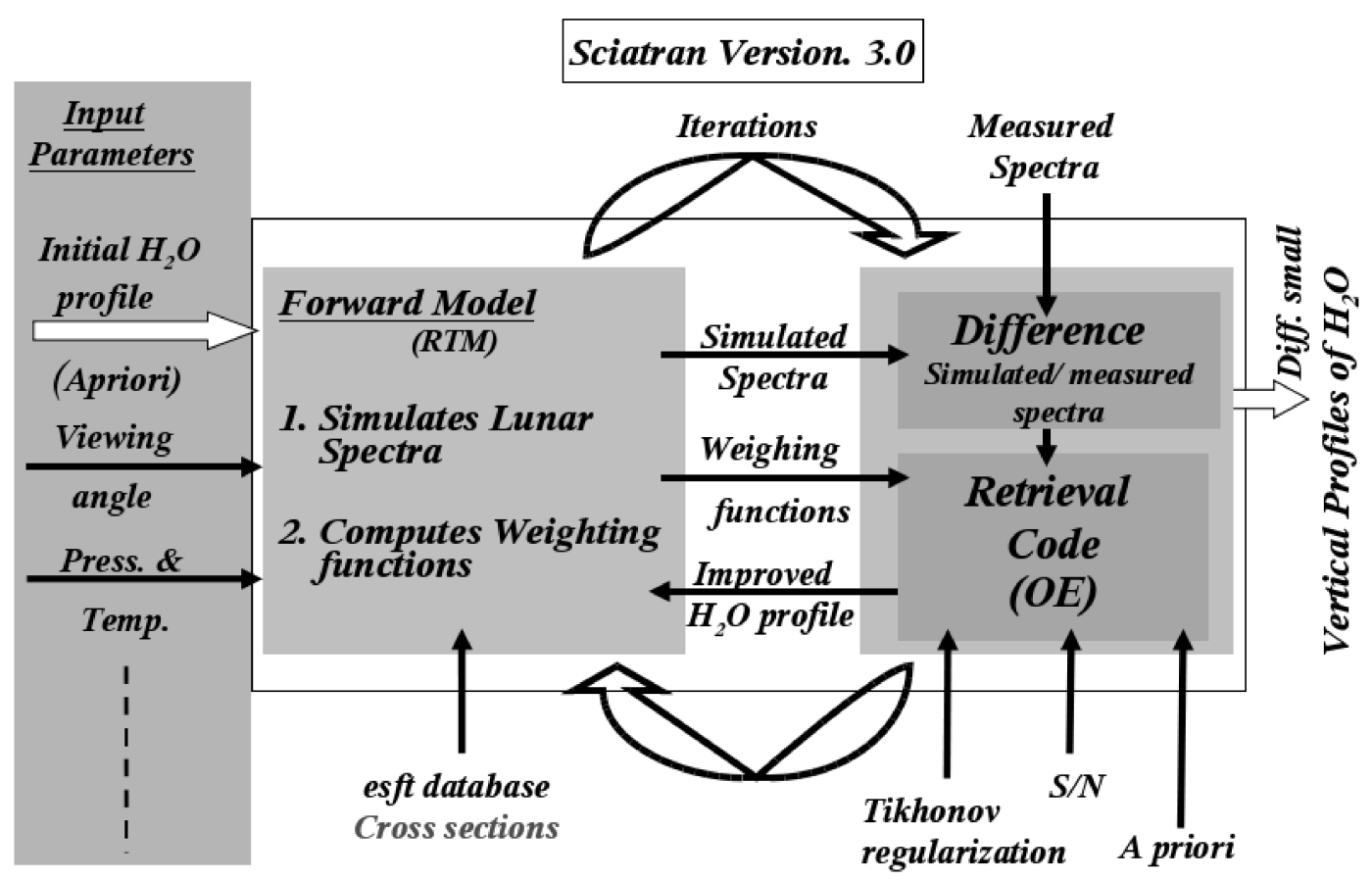

Fig. 7. SCIATRAN: setup for the retrieval by ESFT method. The functioning of forward model and the retrieval parts are elaborated here.

For the construction of the forward model, the differential optical depths were considered rather than the radiances themselves (Rozanov et al., 2000, 2005). This took into account the logarithm of the measured radiances. The logarithms increase the linearity of the inverse method applied; the increased linearity is due to the fact that the fundamental physics is the transmission of the light. The logarithms thereby reduce the linearization errors (Hoogen et al., 1999; Rozanov et al., 2011). A fitted third order (low order) polynomial $P(3)$ in wavelength $\lambda$ was then subtracted to reduce the effect of the broad band features. This whole approach was applied to the measured radiance at each tangent height $j$, the radiance at the reference tangent height (note: both are represented by one Eq. 8) and the simulated radiances.

$$
\begin{aligned}
\tilde{I}_{j}(\lambda) & =\ln \left[I_{j}(\lambda)\right]-P(3) \\
& =\left[I_{j}(\lambda)\right]-\sum_{i=0}^{N=3} c_{i} \lambda^{i}
\end{aligned}
$$

Here, $c$ is the coefficient of the polynomial, and $i$ is the polynomial index. Spectra of differential optical depths were used. To obtain them, the radiance spectra were divided by the reference spectrum (at $120 \mathrm{~km}$ altitude). This implies, numerically,

$y_{j}=\frac{\ln \left(\widetilde{I}_{j}(\lambda)\right)}{\ln \left(\widetilde{I}_{\mathrm{ref}}(\lambda)\right)}$.

The simulated transmission differential spectra defining the forward model were obtained in a very similar manner.
The variation or the response of the measured radiation due to the change in the vertical profile of the atmospheric parameter $\alpha^{k}$ (where $k$ is the retrieval parameter index) at a spectral point $\lambda$ is mathematically termed the weighting function at the altitude $h_{j}$ under consideration. The weighting functions are elements of the matrix $\mathbf{K}$, from Eq. (3), and hence are the derivatives of the measured intensity $I_{j}$ with respect to the relative trace gas concentration $\alpha^{k}$,

$W_{j}^{k}(\lambda)=\frac{\partial I_{j}(\lambda)}{\partial \alpha^{k}} \alpha^{k}$.

These are the relative weighting functions and are also transformed to the differential form for the same reason described above. Thus

$\tilde{W}_{j}^{k}=\frac{1}{I_{j}^{\mathrm{s}}(\lambda)} W_{j}^{k}-\frac{1}{I_{\mathrm{ref}}^{\mathrm{s}}(\lambda)} W_{\mathrm{ref}}^{k}-\sum_{i=0}^{N=3} c_{i} \lambda^{i}$.

Here, $I^{\mathrm{s}}$ are the simulated differential spectra. For the lunar occultation, the effect of errors resulting from wavelength calibration and Doppler shift, etc., were reduced by applying a shift and squeeze correction. Such correction of individual spectra improves wavelength misalignments between weighting functions, radiances and reference spectra. In our study, the correction was carried out by applying nonlinear least squares method, with iterations, thereby reducing the following quadratic form for each tangent height. 


$$
\begin{aligned}
& \| \widetilde{I}_{j}^{\mathrm{s}}(\lambda)+\sum_{k} \tilde{W}_{j}^{k}(\lambda) \frac{\Delta \alpha^{k}}{\alpha^{k}}-\tilde{I}_{j}(\lambda)+\tilde{I}_{\mathrm{ref}}(\lambda) \\
& -\left(b_{\mathrm{sh}}-b_{\mathrm{sq}} \lambda\right) \frac{\delta \widetilde{I}_{j}^{\mathrm{s}}(\lambda)}{\delta \lambda}-\left(b_{\mathrm{sh}}^{\prime}-b_{\mathrm{sq}}^{\prime} \lambda\right) \frac{\delta \tilde{I}_{\mathrm{ref}}(\lambda)}{\delta \lambda} \|^{2} \rightarrow m
\end{aligned}
$$

In the above equation, $W_{j}^{k}(\lambda)$ are the vertically integrated weighting functions with scaling of the vertical profile as $\Delta \alpha^{k} / \alpha^{k}$, which is constant for each layer. $b_{\mathrm{sh}}, b_{\mathrm{sq}}, b_{\mathrm{sh}}^{\prime}$ and $b_{\mathrm{sq}}^{\prime}$ are the shift and squeeze parameters for the spectra at a given tangent altitude at $j$ and at the reference height, respectively. This pre-processing step by SCIATRAN improved the residuals, especially for the lower stratospheric tangent heights.

\subsubsection{Inversion/retrieval part}

The theoretical aspects of the retrieval technique are explained in Sect. 4, which involve solving the inverse problem by implementation of the optimal estimation to get the desired parameter and applying Newton iterative scheme for the convergence of the solution. The retrieval procedure is sketched in Fig. 7. As shown in the figure, the retrieval can be divided into two parts. In the first part, the difference between the measured and the simulated spectrum is calculated. The second part takes the parameters a priori, signal to noise ratio and Tikhonov regularization and applies optimal estimation on the result from the former composing the vertical profile of water vapor. The optimizations related to signal to noise ratio and Tikhonov regularization parameter will be discussed in the next section. The profile obtained is fed back to the forward model section where the simulation and computations are done again. A number of iterations are carried out until the conditions described in Sect. 4 are achieved. The final retrieval profile, approximating the true atmospheric state, was obtained in this manner.

\subsubsection{The line absorber treatment}

As mentioned before in Sect. 5.4, the line absorber treatment is carried out using ESFT approximation (Wiscombe and Evans, 1977) employing correlated- $k$ approach and not the LBL method. The LBL radiative transfer is a monochromatic method involving computations of radiance for each frequency in a selected wavelength window. The radiances are then integrated over this region. It should be noted that the LBL method is assumed to be a true representative of the reality compared to the ESFT approximation. LBL computation has to be carried out with a sufficiently fine grid $(0.001 \mathrm{~nm} /$ line or less) to accurately reproduce the absorption coefficient spectrum and to perform correct radiative transfer calculations. The LBL calculations thus require substantial computing time. ESFT is preferred over LBL since it provides a good compromise between efficiency and accuracy. When LBL is used in SCIATRAN, the line parameters, as line intensities, line locations, etc., are taken from HITRAN 2008.

By definition, ESFT is a method of fitting the transmission functions by exponential sums to calculate the spectrally integrated radiative fluxes. In the correlated- $k$ distribution method, the spectrum is binned according to the strength of absorption, and the radiative transfer equation is integrated for all atmospheric layers under consideration. The binning is based on the observations that the maxima and minima of absorptions in different layers coincide spectrally. The implementation of this method in SCIATRAN is discussed in detail in Buchwitz et al. (2000). ESFT is a fast retrieval method and its usage in SCIATRAN involves the calculation of the ESFT coefficients using HITRAN 2008 database. Mathematically, in general, the absorption coefficients for simple LBL computation are given as

$k_{\lambda}(p, t)=\sum_{i} S_{i}(t) f_{i}(\lambda, p, t)$,

where $p$ and $t$ are pressure and temperature, respectively. $S_{i}$ is the line intensity for the ith absorption line, and $f_{i}(\lambda, p, t)$ stands for the line shape factor. The spectral mean transmittance over the spectral interval $\Delta \lambda$ can be approximated as

$T_{\Delta \lambda}(m)=\int_{\Delta \lambda}\left[\exp \left(-k_{\lambda} m\right)\right] \frac{d \lambda}{\Delta \lambda}$,

where $m$ is the absorber amount per unit area. In a given wavelength window, the same values of $k(p, t)$ occur frequently. This means that the computational efficiency can be improved by replacing the integration over $\lambda$ in Eq. (14) by the probability distribution function of absorption coefficient $h(k)$, and further by their cumulative probability distribution $g(k)$ : (Fu and Liou, 1992; Li and Barker, 2004)

$$
T_{\Delta \lambda}(m)=\int_{0}^{\infty}\left[\exp \left(-k_{\lambda} m\right)\right] h(k) d(k)=\int_{0}^{1}\left[\exp \left(-k_{g} m\right)\right] d g .
$$

$h(k) d k$ is the fraction of $\Delta \lambda$ where the absorption coefficient value is between $k$ and $k+d k$, and by definition $g(k)$ is a monotonically and smoothly increasing function in $k$ space.

$g(k)=\int_{0}^{1} h(k) d k$

At different temperature/pressure in the atmosphere, the cumulative probability distribution space of the absorption coefficients are correlated (Kratz et al., 1998). For such a correlation of absorption coefficients, an optimum number of $k$ values can be selected to further reduce the computing time. The optimization method of choice in this case is the ESFT approximation. In the ESFT approach, the spectral mean transmission is approximated by a quadrature of 


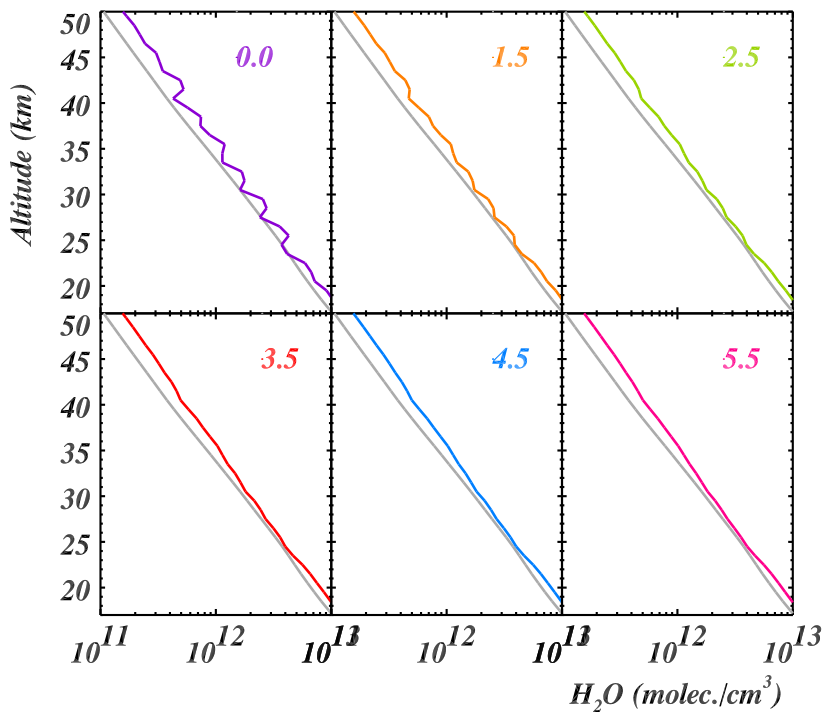

Fig. 8. Number density profiles with different Tikhonov parameters: The coloured lines are the retrieved water vapor profiles using different Tikhonov values and the grey lines in each panel are the a priori profiles. Tihkonov parameter 3.5 was selected for the retrieval (Measurement: 13 March 2006, orbit=21085, $\mathrm{SZA}=109.137$, moon phase $=0.93$ ).

absorption coefficients $k_{i}(p, t)$ with weights $w_{i}$ and nodes $g_{i}$.

$T_{\Delta \lambda}(m)=\sum_{i=0}^{n} w_{i}\left[\exp \left(-k_{\lambda} m\right)\right]$

where $k_{i}=k\left(g_{i}\right)$ and $\sum_{i} w_{i}=1$

HITRAN 2008 database for ESFT implementation contains the spectral ranges, their corresponding line absorbers, and as explained above, the number of coefficients calculated at a number of temperature and pressure grid points for each case. As will be seen in the next section, in our study, different grids for the water vapor window $1240-1560 \mathrm{~nm}$ created at the Institute of Environmental Physics (IUP) were tested for the retrieval.

\subsubsection{Sensitivity studies and optimizations}

To account for the finite spectral resolution of the instrument, the simulated radiance has to be convolved with an appropriate instrument slit function. In ESFT technique, the internal wavelength grid for convolution is read from ESFT database for the RTM calculations.

The signal to noise ratio was estimated from the fit residuals at the preprocessing step.

The smoothness of the retrieval profile was constrained by applying Tikhonov regularization (Eq. 6). Figure 8 shows the number density profiles for different Tikhonov parameters, and Fig. 9 shows the theoretical errors arising from these

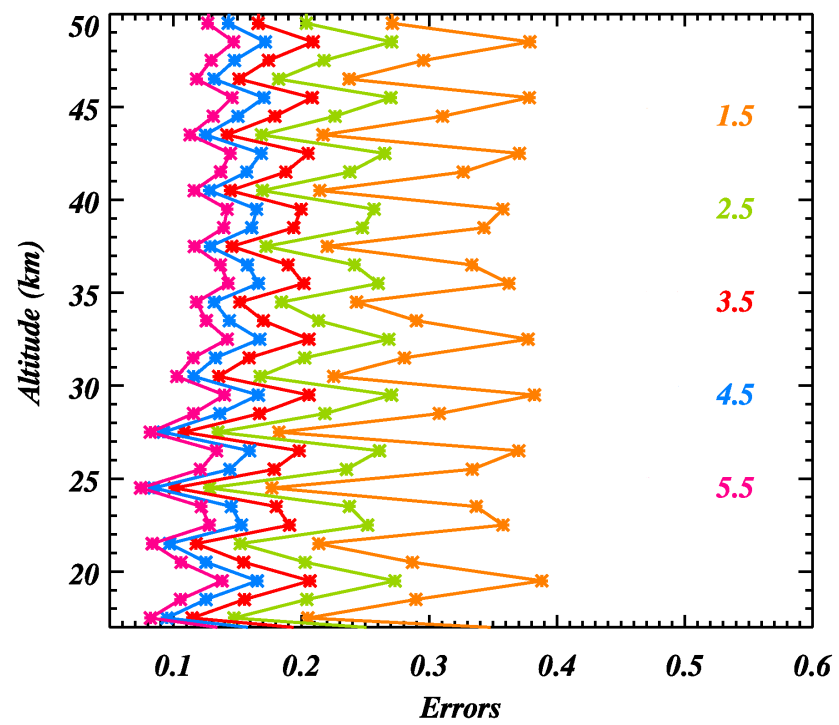

Fig. 9. Theoretical error profiles corresponding to the profiles in Fig. 8 (except for 0.0): Errors are within a reasonable range for the selected Tikhonov value of 3.5.

Table 1. Pressure, Temperature and Coefficients Database Grids: ESFT retrieval was performed using different pressure, temperature and coefficients grids.

\begin{tabular}{lrc}
\hline Pressure & Temperature & Coefficients \\
\hline 10 & 9 & 10 \\
20 & 9 & 10 \\
32 & 9 & 10 \\
$32^{*}$ & 9 & 10 \\
32 & 22 & 10 \\
32 & 22 & 15 \\
\hline
\end{tabular}

* The fourth row in the Table 1 above, indicates the same grid as in the third row but with different distribution of pressures and temperatures.

selected numbers. It can be seen that the higher values of the smoothness parameter cause loss of information (Fig. 8), keeping the errors low while the lower values are unable to remove the oscillations and introduce errors. An appropriate Tikhonov value, 3.5, was selected, preventing loss of measurement information.

As mentioned before, convolution is applied to the simulated spectrum according to the instrument slit function. A Gaussian type slit function was used. The parameter defining the width of the slit function is the full width at half maximum (FWHM). Since knowledge about SCIAMACHY slit function is limited, the value for the FWHM was optimized with respect to the fit residuals. The value of FWHM giving minimum retrieval residuals was selected. The residuals were found to be minimum at the FWHM of $1.30 \mathrm{~nm}$.

Following the sensitivity studies, the quality of the retrieval performed using ESFT technique was first verified 


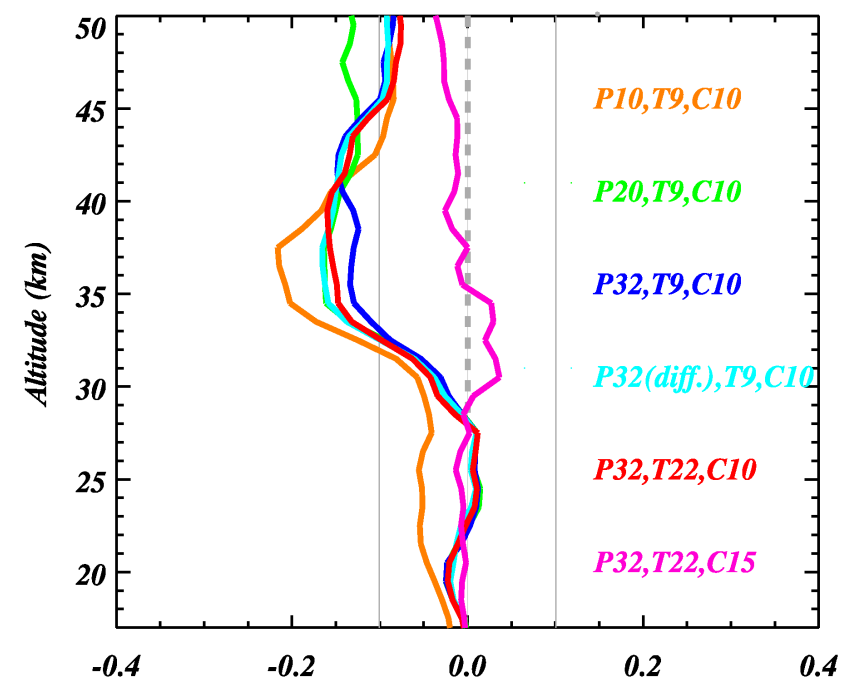

Fig. 10. The LBL-ESFT comparison for the year 2008: ESFT retrieval performed at different grids with different pressure, temperature, and number of coefficients and compared with LBL. The results are shown as the relative mean differences, i.e. mean (LBL-ESFT)/LBL.

by comparison with the profiles retrieved from the LBL. As mentioned earlier, compared to the ESFT approximation, theoretically LBL is considered to be the true representative of reality. Owing to the computational cost, the lunar occultation spectra were retrieved by using LBL method for only one randomly selected year, 2008. For the same year, the ESFT retrieval was performed using grids with different pressure $(P)$, temperature $(T)$ and coefficients $(C)$ as shown in Table 1.

The objective was to make the ESFT retrieved profiles agree with the line by line retrieval. Figure 10 illustrates the results of the comparisons as the relative mean difference plots for the profiles of 2008 retrieved on different ESFT grids. As can be observed in the figure, changing the number of pressure and temperature grid points has less impact on the results. Increasing the number of coefficients (from 10 to 15$)$ is seen to bring the two techniques in good agreement, specifically, as clear in the figure, the LBL-ESFT difference is reduced from $15-20 \%$ to around $3.5 \%$ in the middle stratosphere. It should be mentioned here that increasing the number of coefficients increases the computational time. Conclusively, the grid with 32 pressures, 22 temperatures and 15 coefficients was found to give the closest match between the ESFT and LBL retrieval, where the overall LBL-ESFT agreement is within 1 to around $3.5 \%$ from $17-50 \mathrm{~km}$.

\section{Averaging kernels}

Equation (5) describes the gain matrix, which signifies the sensitivity of the retrieved profile to the measurement. The sensitivity of the profile to the true profile is given by
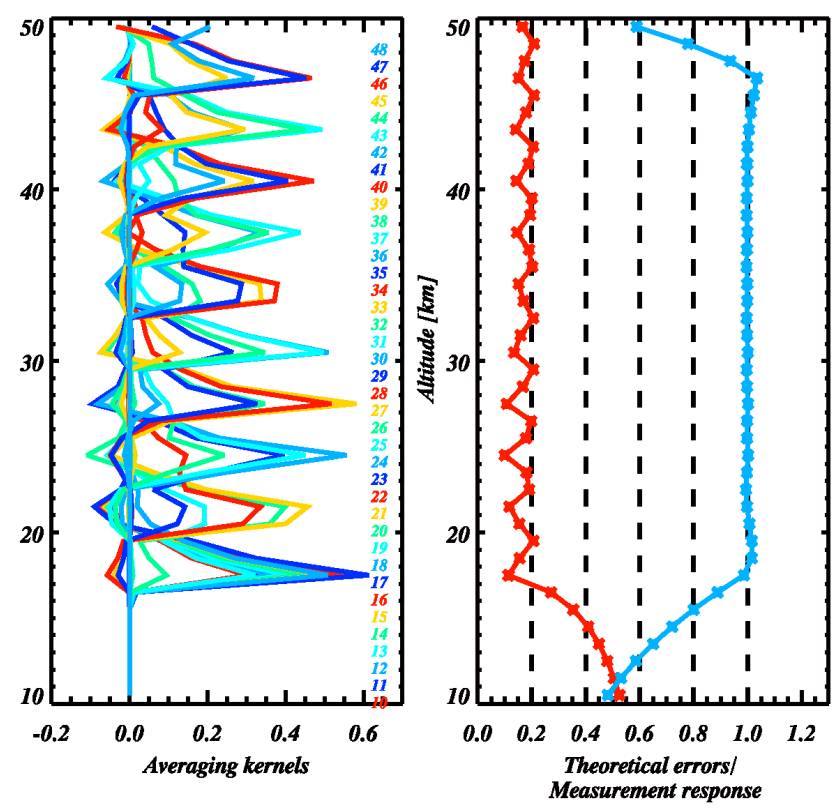

Fig. 11. The left panel shows the averaging kernels and the right panel shows the theoretical errors (red line) and the measurement response function (blue line). The measurement is on 13 March 2006, orbit $=21085, \mathrm{SZA}=109.137$ and the moon phase $=0.93$.

the averaging kernel matrix $\mathbf{A}$, where $\mathbf{A}=\mathbf{D K}, \mathbf{A} \approx \partial \hat{\boldsymbol{x}} / \partial \boldsymbol{x}$. Therefore

$\mathbf{A}=\left(\mathbf{K}_{i}^{T} \mathbf{S}_{y}^{-1} \mathbf{K}_{i}+\mathbf{S}_{\mathrm{a}}^{-1}\right)^{-1} \mathbf{K}_{i}^{T} \mathbf{S}_{y}^{-1} \mathbf{K}$.

Along with sensitivity of the retrieval, the averaging kernel matrix also characterizes its vertical resolution. At a given altitude, the averaging kernels are peaked functions. The vertical resolution is given by their width where a measure of the width at a given height can be FWHM, see Sect. 5.4.4. The sum of all elements (rows) of the averaging kernel matrix is often termed the measurement response in the literature (Rodgers, 2000). When it is close to unity, the observing system is sensitive to the true profile. Values less than unity signify the influence of the a priori on the retrieval.

The averaging kernels for SCIAMACHY lunar occultation water vapour retrieval employing the ESFT approach in the RTM are shown in Fig. 11. The averaging kernels are based on the $1 \mathrm{~km}$ grid SCIATRAN used in the forward model. The reason for using the retrieval grid here is that the forward model does not recognize the instrument FOV that could be used instead, and a $1 \mathrm{~km}$ grid is needed for accurate radiative transfer computations. The averaging kernels of several altitudes have peaks at the same level due to the difference between SCIAMACHY's vertical sampling $(3.3 \mathrm{~km})$ and the retrieval grid $(1 \mathrm{~km})$. In general, the averaging kernels below $47 \mathrm{~km}$ have sharp peaks, indicating high sensitivity of the retrieval for this range. The response function plotted in the right panel of Fig. 11 shows that between 17 and $47 \mathrm{~km}$, 


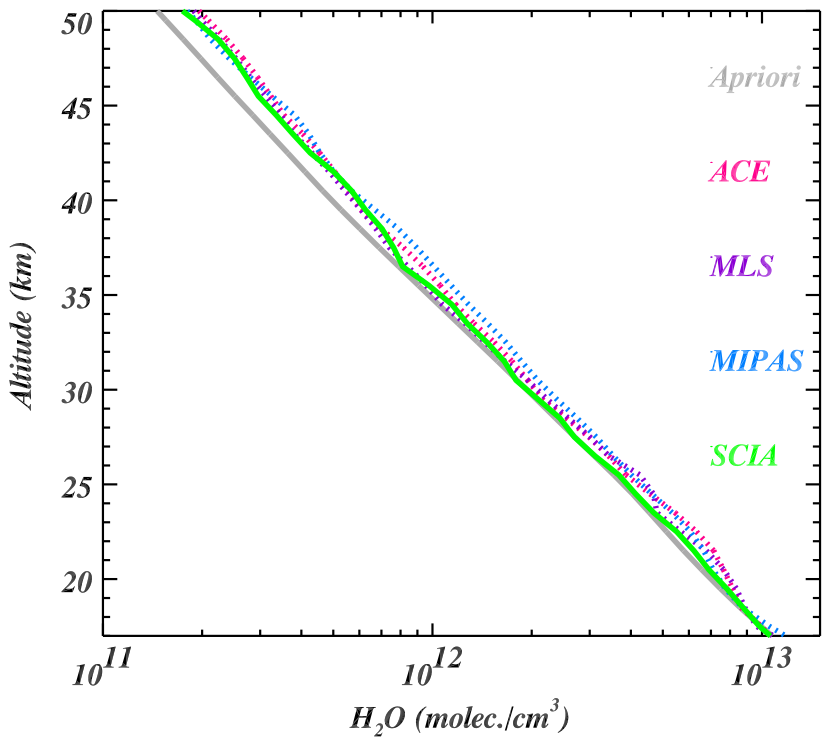

Fig. 12. An example of the retrieved SCIAMACHY lunar occultation water vapor profile from 10 January 2009, orbit number 35889. For this measurement three collocations are found with ACE-FTS(ss29145), MLS(T505691134), MIPAS(35894).

the retrieval profile is determined only by the measurement (value $\approx 1$ ). Above $47 \mathrm{~km}$ there is some contribution from the a priori (value $<1)$.

\section{Water vapor profiles}

Figure 12 gives an example of the retrieved SCIAMACHY lunar occultation water vapor number density profile for the southern polar stratosphere from $17-50 \mathrm{~km}$. The profile is for 10 January 2009. The correlative ACE-FTS (Atmospheric Chemistry Experiment Fourier Transform Spectrometer), MLS (Microwave Limb Sounder) and MIPAS (Michelson Interferometer for Passive Atmospheric Sounding) are also plotted in the figure. The water vapor volume mixing ratios (vmr) from these four instruments were converted to number densities using the temperatures and pressures measured by these instruments. The number densities were then interpolated to the retrieval altitude grid of SCIAMACHY measurements for comparison.

\section{Comparisons/validations}

To assess the quality of the SCIAMACHY lunar occultation water vapor profiles, the validation was performed with collocated measurements from the satellite instruments ACEFTS and HALOE (Halogen Occultation Experiment), which are occultation instruments, and MLS and MIPAS, which perform measurements in the limb geometry. The SCIAMACHY water vapor data showed evidence of PSC as early as May. Such PSCs contaminated profiles were filtered out

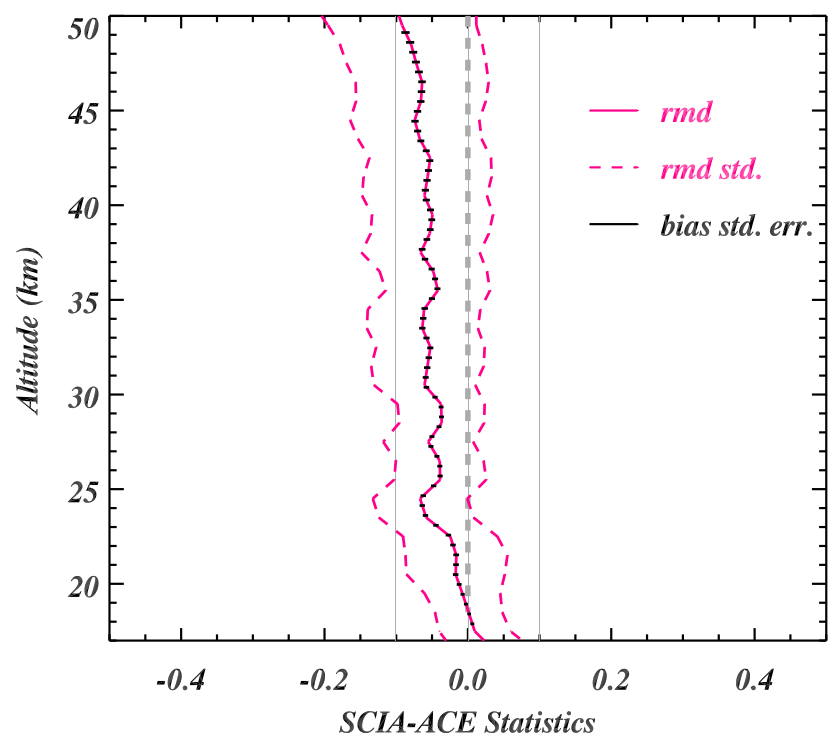

Fig. 13. SCIAMACHY-ACE comparison statistics for the period 2004-2009 based on 302 collocations with combined ACE-FTS sunrise and sunset events.

on the basis of the temperature thresholds for the production of all types of PSCs. The formation temperature for the type I PSCs, i.e. nitric acid trihydrate (NAT, crystalline), is less than $195 \mathrm{~K}$, and the type II PSCs, i.e. pure ice, can form at temperatures lower than approximately $188 \mathrm{~K}$ (von Savigny et al., 2005; Peter, 1997). The ECMWF analysis profiles corresponding to the SCIAMACHY water vapor profiles were used as the source of temperature information.

For the comparison with SCIAMACHY data, as mentioned before, the water vapor vmr from the four instruments were converted to number densities. The coincidence search was based on the criteria of selecting all the measurements within the maximum collocation radius of $1000 \mathrm{~km}$ and having a maximum time difference of $12 \mathrm{~h}$ between SCIAMACHY overpass and the correlative measurements from the instruments.

The comparisons are plotted showing the following statistics:

- rmd: The relative mean difference between the SCIAMACHY and other instrument weighted by the average.

- rmd std.: The standard deviation of the ensemble of relative mean differences giving an insight into the variability of the individual comparisons.

- bias std. err: The rmd can be seen as measurement of the bias of SCIAMACHY to the other instrument. The standard error of the bias is the standard deviation of the ensemble divided by the square root of the number of coincidences. 


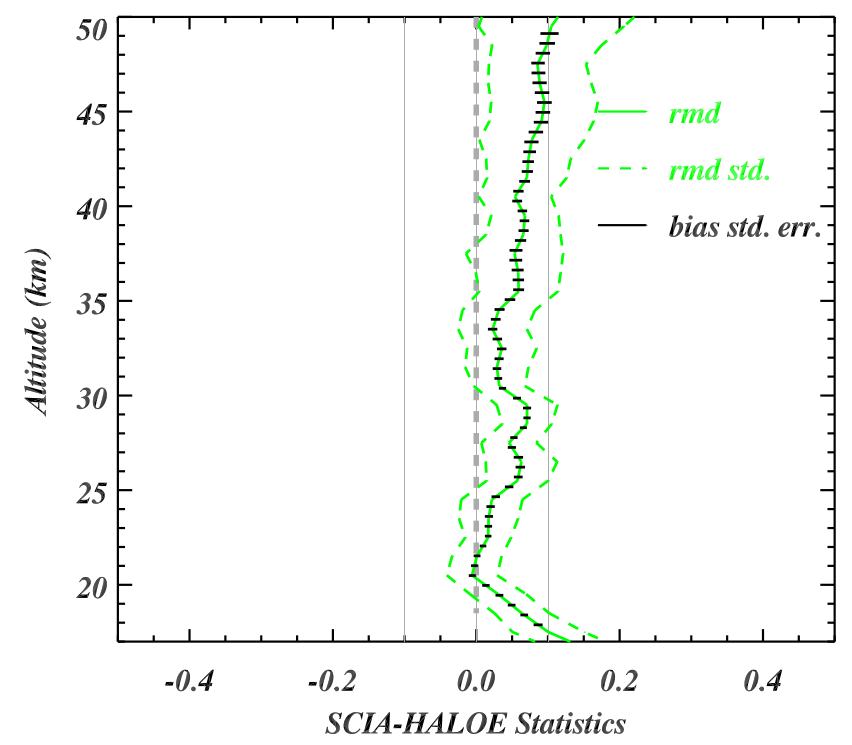

Fig. 14. SCIAMACHY-HALOE comparison statistics for the period 2003-2005 based on 52 collocations with HALOE sunrise events (none was found with the sunset events).

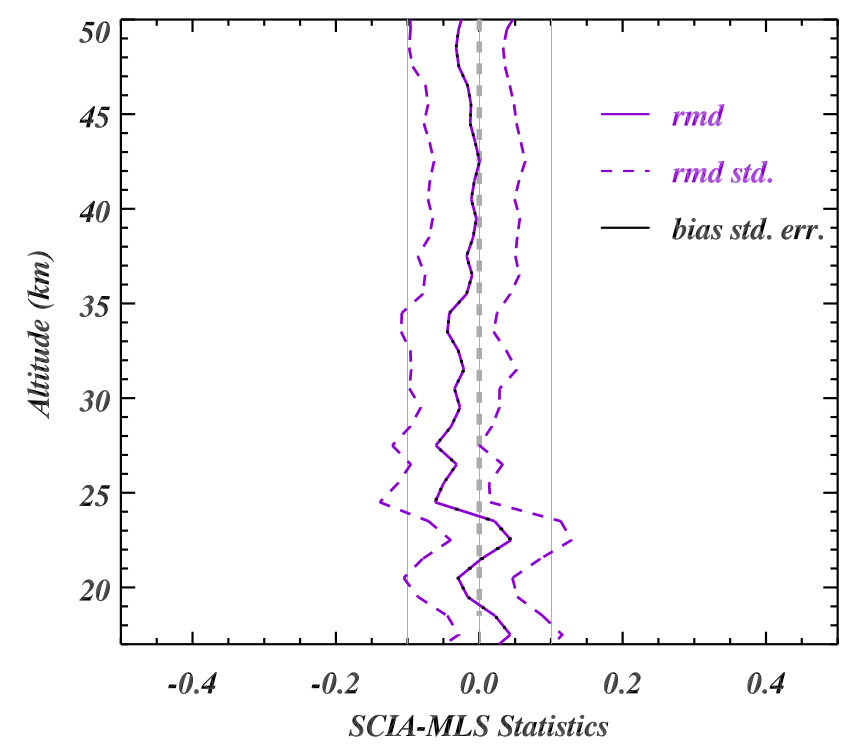

Fig. 15. SCIAMACHY-MLS comparison statistics for the period 2004-2010 based on 1321 collocations.

As clear in Figs. 13, 14, 15 and 16, the standard error of the bias is very small in all cases as the number of coincidences is large. All biases discussed in the following section are significant with respect to their standard errors.

\subsection{ACE-FTS}

The Atmospheric Chemistry Experiment Fourier Transform Spectrometer (ACE-FTS) onboard Canadian scientific satellite SCISAT has been performing solar occultation measurements in the infrared since 2004 (Bernath, 2005). The

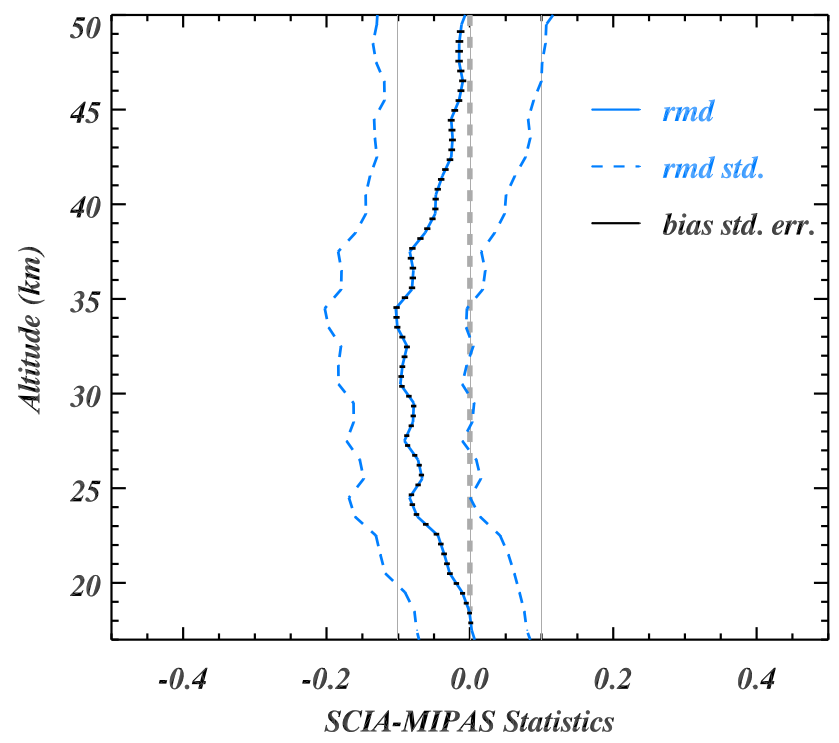

Fig. 16. SCIAMACHY-MIPAS comparison statistics for the period 2005-2010 based on 489 collocations.

vertical resolution of the instrument is consistent with that of SCIAMACHY lunar occultation, which is $3-4 \mathrm{~km}$. The water vapor vmr from ACE-FTS are retrieved from 5 to $90 \mathrm{~km}$ (Carleer et al., 2008). For the presented study, ACE-FTS version 2.2 water vapor product was used. The comparisons of this version of ACE with various ground-based and spaceborne instruments have shown that ACE-FTS is biased positive (wet bias) on the order of 3-10\% between $15-70 \mathrm{~km}$, according to Carleer et al. (2008).

With the collocation criteria described above and for the period of 2004-2009, 302 collocations were found for both sunrise and sunset ACE-FTS events. Figure 13 shows the statistics plotted for the altitude range $17-50 \mathrm{~km}$. The SCIAMACHY-ACE rmd are observed to be within $-1.5 \%$ from 17 to $22 \mathrm{~km}$, about $-5 \%$ for $23-42 \mathrm{~km}$, around -6 to $-7 \%$ between $43-47 \mathrm{~km}$, and within $-10 \%$ for the altitude range $48-50 \mathrm{~km}$. Hence, in general the rmd are below $-7 \%$. The rmd std. are within $5 \%$ from 17 to $29 \mathrm{~km}$ and increase to $7-10 \%$ from 30 to $50 \mathrm{~km}$. The above mentioned wet bias in ACE-FTS water vapor measurements is also seen by SCIAMACHY lunar occultation measurements. From this evidence, it can be concluded that the SCIAMACHY-ACE agreement is good, being well within the reported biases of ACE-FTS.

\subsection{HALOE}

The Halogen Occultation Experiment (HALOE) was launched on Upper Atmosphere Research Satellite (UARS) in 1991 (Russell et al., 1993b), and the mission ended in 2005. HALOE used infrared solar occultation to measure the vertical profiles of different climate parameters from 15 to $85 \mathrm{~km}$ with a vertical resolution of around $2.3 \mathrm{~km}$. 
The version 19 of HALOE water vapor profiles was used in our study. The extensive validations of HALOE water vapor measurements have shown that HALOE is biased low (dry bias) by $5 \%$ in the stratosphere (Harries et al., 1996; Kley et al., 2000).

The coincidence search with the criteria employed for the years 2003-2005 resulted in 52 coincidences with HALOE sunrise events and none with sunset. Figure 14 shows the statistics of SCIAMACHY-HALOE comparisons. The rmd are $10 \%$ at $17 \mathrm{~km}, 6 \%$ at $18 \mathrm{~km}$, about $1 \%$ between 19 $24 \mathrm{~km}$, vary around $5 \%$ from 25 to $40 \mathrm{~km}$, within $7.5 \%$ for $41-43 \mathrm{~km}$ and reach about $10 \%$ at $50 \mathrm{~km}$. The rmd std. vary between $3.5-4.5 \%$ from 17 to $33 \mathrm{~km}, 5-6 \%$ at $34-42 \mathrm{~km}$, around $7.5 \%$ for the altitudes $43-48 \mathrm{~km}$ and then $10 \%$ to $50 \mathrm{~km}$. Keeping the dry bias in the HALOE measurements in view, the SCIAMACHY-HALOE difference is indicative of the influence of the HALOE bias in the comparisons.

\subsection{MLS}

The EOS-MLS (Earth Observing System-Microwave Limb Sounder) was launched on NASA's satellite EOS-Aura in 2004. MLS makes atmospheric measurements from 8 to $90 \mathrm{~km}$ by observing thermal microwave emissions from the Earth's limb (Waters et al., 2006; Schoeberl et al., 2006). In the altitude region of about $18-54 \mathrm{~km}(100-1.0 \mathrm{hPa})$, the vertical resolution of MLS is $3.5-4.6 \mathrm{~km}$. MLS water vapour version 2.2 was used for the validation of lunar occultation water vapour profiles because it is an extensively validated MLS water vapor product. For the comparison, the MLS geopotential height was converted to geometric height using the MLS pressure and temperature.

The SCIAMACHY-MLS validation was based on 1321 collocated measurements for the period 2004-2010. The comparison result is shown in Fig. 15 where the rmd vary between $1.5-4 \%$ from $17-34 \mathrm{~km}$ with exceptions at about 22, 24 and $27 \mathrm{~km}$ where it is in the range of $\pm 4.5-6 \%$. The rmd are within -1 to $-1.5 \%$ for $35-46 \mathrm{~km}$, and within $-3 \%$ from 47 to $50 \mathrm{~km}$. The rmd std. range between $6-7.5 \%$ for the whole altitude of $17-50 \mathrm{~km}$. It should be noted here that in its comparisons with other satellite instruments including ACE-FTS, HALOE and MIPAS, the MLS water vapor version 2.2 is noted (Lambert et al., 2007) to exhibit sharp differences or kinks around $26.1-31.6 \mathrm{hPa}$, which is the region within a few kilometres from $25 \mathrm{~km}$. This problem is corrected in the MLS version 3.3 processing algorithm. The SCIAMACHY-MLS exceptional agreement, apart from the above mentioned difference arising due to MLS, validates the good quality of our retrieval and the lunar occultation water vapor dataset. Moreover, MLS, measuring in the microwave, is far less sensitive to clouds and aerosols (Livesey et al., 2006; Waters et al., 2006) that may contaminate any other shorter wavelength region. The SCIAMACHY-MLS excellent agreement shows that the lunar occultation water vapor measurements used for the validations are void of any contaminations.

\subsection{MIPAS}

MIPAS (Michelson Interferometer for Passive Atmospheric Sounding) is one of the ten instruments including SCIAMACHY onboard Envisat satellite. The instrument is a midinfrared limb emission Fourier transform spectrometer measuring atmospheric profiles of temperature and various constituents of atmosphere from 6-68 km (Fischer et al., 2008). The vertical resolution of MIPAS varies from around $2.3 \mathrm{~km}$ (at $20 \mathrm{~km}$ ) to about $6.9 \mathrm{~km}$ (at $50 \mathrm{~km}$ ) (von Clarmann et al., 2009). The water vapor data version V40_H2O_203 retrieved from the IMK-IAA data processor was used in the presented comparison. The comparison of this MIPAS water vapor data is performed with various ground-based and satellite instruments in the framework of the MOHAVE-2009 campaign, which took place at a location of $34.4^{\circ} \mathrm{N}, 117^{\circ} \mathrm{W}$ on 12 26 October 2009. The details and results of this study are reported in Stiller et al. (2012). It must be noted that the aim of this campaign was to compare the MIPAS data primarily with highly accurate and precise ground-based and balloonborne measurements. The MIPAS water vapor profiles are reported to be within $\pm 10 \%$ of the profiles of the correlative measurements of most of the instruments, which is within the bias regime among ground-based instruments comparisons.

With the collocation criteria as employed in our study, and for the period of 2005-2010, 489 correlative incidences were found between SCIAMACHY and MIPAS. Figure 16 shows the SCIAMACHY-MIPAS comparison results. The rmd are within -1 to $-4.5 \%$ from 17 to $22 \mathrm{~km}$, around $-7.5 \%$ at $23-26 \mathrm{~km}$, reach $-9 \%$ for the altitude range $27 \mathrm{~km}$ to about $38 \mathrm{~km},-2.5$ to $-4.5 \%$ between 39 to $44 \mathrm{~km}$ and within $-1.5 \%$ for $45-50 \mathrm{~km}$. The rmd std. are about $7.5 \%$ and gradually reach $10 \%$ at $50 \mathrm{~km}$. The SCIAMACHY-MIPAS agreement is within the above mentioned MIPAS bias.

\section{Conclusions and outlook}

The SCIAMACHY lunar occultation measurements have been used to derive the water vapor profiles for the southern hemispheric high latitudes. The retrieval optimizations and sensitivity studies are stepwise presented here. We have demonstrated that for the ESFT method employed with correlated- $k$ approach, the number of coefficients is crucial for the quality of the retrieval. A close agreement between ESFT and LBL can be achieved by increasing the number of coefficients and thus reducing any systematic biases in the resulting ESFT profiles to below $3 \%$ on the average. The SCIAMACHY lunar occultation water vapor measurement comparisons with the collocated ACE-FTS, HALOE, MLS and MIPAS measurements have shown agreements that are well within the reported and published uncertainties/biases 
of these instruments. Based on the presented validations, we can conclude that with SCIAMACHY lunar occultation we have retrieved a scientifically useful water vapor product (version 1.0).

From the SCIAMACHY lunar occultation, the retrieval of water vapor is successfully carried out in the NIR, implying that other gases with spectral signatures in the same region, as methane, $\mathrm{CH}_{4}$ and carbon dioxide, $\mathrm{CO}_{2}$, can also be retrieved from lunar occultation.

For the southern hemispheric stratosphere, the in situ water vapor measurements are still in their initial stages and are not available for validation purposes. The SCIAMACHY lunar occultation water vapor dataset is valuable for the southern hemispheric stratospheric region. The product can be used in the models investigating polar vortex dynamics. With these measurements, the formation of PSCs can be studied as early as May-June for the southern region. The dataset is expected to give good results in interpretations and analyses studies. The lunar occultation water vapor measurements will add as a southern hemispheric coverage to the SCIAMACHY long-term global water vapor time series.

Acknowledgements. We are thankful to the following: ESA ENVISAT for providing the SCIAMACHY level 1 data. The Atmospheric Chemistry Experiment (ACE) also known as SCISAT, a Canadian-led mission mainly supported by the Canadian SPACE agency and Natural Sciences and Engineering Research Council of Canada. The EOS-MLS (NASA's mission EOS-AURA). The MIPAS team at Karlsruhe Institute of Technology for providing the data and the updates. The study is funded by the BMBF, DLR-Bonn via grant 50EE0727 and by the University of Bremen.

Edited by: A. J. M. Piters

\section{References}

Abbas, M. M., Gunson, M. R., Newchurch, M. J., Michelsen, H. A., Salawitch, R. J., Allen, M. L., Abrams, M. C., Chang, A. Y., Goldman, A., Irion, F. W., Moyer, E. J., Nagaraju, R., Rinsland, C. P., Stiller, G. P., and Zander, R.: The hydrogen budget of the stratosphere inferred from ATMOS measurements of $\mathrm{H}_{2} \mathrm{O}$ and $\mathrm{CH}_{4}$, Geophys. Res. Lett., 23, 2405-2408, doi:10.1029/96GL01320, 1996.

Amekudzi, L., Bracher, A., Meyer, J., Rozanov, A., Bovensmann, H., and Burrows, J. P.: Lunar occultation with SCIAMACHY, First retrieval results, Adv. Space Res., 5, 906-914, 2005.

Amekudzi, L. K.: Stratospheric $\mathrm{O}_{3}, \mathrm{NO}_{2}$, and $\mathrm{NO}_{3}$ number density profiles from SCIAMACHY lunar occultation spectroscopic measurements: Retrieval, validation and interpretation, Ph.D. thesis, Universität Bremen, 2005.

Amekudzi, L. K., Bramstedt, K., Rozanov, A., Bovensmann, H., and Burrows, J. P.: Retrievals of trace gas concentratioins from lunar occultation measurements with SCIAMACHY on ENVISAT, in: New Horizon in occultation Research: Studies in Atmosphere and Climate, Springer, Berlin, Heidelberg, 87-96, 2009.
Bernath, P. F.: Atmospheric Chemistry Experiment (ACE): Mission overview, Geophys. Res. Lett., 32, 1-5, doi:10.1029/2005GL022386, 2005.

Bovensmann, H., Burrows, J. P., Buchwitz, M., Frerick, J., Noel, S., Rozanov, V. V., Chance, K. V., and Goede, A. P. H.: SCIAMACHY: Mission Objectives and Measurement Modes, J. Atmos. Sci., 56, 127-150, doi:10.1175/15200469(1999)056<0127:SMOAMM > 2.0.CO;2, 1999.

Buchwitz, M., Rozanov, V. V., and Burrows, J. P.: A correlated-k distribution scheme for overlapping gases suitable for retrieval of atmospheric constituents from moderate resolution radiance measurements in the visible/near-infrared spectral region, J. Geophys. Res., 105, 15247-15261, doi:10.1029/2000JD900171, 2000.

Burrows, J. P., Holzle, E., Goede, A. P. H., Visser, H., and Fricke, W.: SCIAMACHY - Scanning Imaging Absorption Spectrometer for Atmospheric Chartography, Acta Astronaut., 35, 445-451, 1995.

Carleer, M. R., Boone, C. D., Walker, K. A., Bernath, P. F., Strong, K., Sica, R. J., Randall, C. E., Vömel, H., Kar, J., Höpfner, M., Milz, M., von Clarmann, T., Kivi, R., Valverde-Canossa, J., Sioris, C. E., Izawa, M. R. M., Dupuy, E., McElroy, C. T., Drummond, J. R., Nowlan, C. R., Zou, J., Nichitiu, F., Lossow, S., Urban, J., Murtagh, D., and Dufour, D. G.: Validation of water vapour profiles from the Atmospheric Chemistry Experiment (ACE), Atmos. Chem. Phys. Discuss., 8, 4499-4559, doi:10.5194/acpd-8-4499-2008, 2008.

Dessler, A. and Kim, H.: Determination of the amount of water vapor entering the stratosphere based on Halogen Occultation Experiment (HALOE) data, J. Geophys. Res., 104, 30605-30607, 1999).

Fischer, H., Birk, M., Blom, C., Carli, B., Carlotti, M., von Clarmann, T., Delbouille, L., Dudhia, A., Ehhalt, D., Endemann, M., Flaud, J. M., Gessner, R., Kleinert, A., Koopman, R., Langen, J., López-Puertas, M., Mosner, P., Nett, H., Oelhaf, H., Perron, G., Remedios, J., Ridolfi, M., Stiller, G., and Zander, R.: MIPAS: an instrument for atmospheric and climate research, Atmos. Chem. Phys., 8, 2151-2188, doi:10.5194/acp-8-2151-2008, 2008.

$\mathrm{Fu}$, Q. and Liou, K. N.: On the correlated k-distribution method for radiative transfer in nonhomogeneous atmospheres, J. Atmos. Sci., 49, 2139-2156, 1992.

Gottwald, M. and Bovensmann, H. (Eds.): Exploring the Changing Earth's Atmosphere, Springer, Dordrecht, Heidelberg, London, New York, doi:10.1007/978-90-481-9896-2, 2011.

Gurlit, W., Zimmermann, R., Giesemann, C., Fernholz, T., Ebert, V., Wolfrum, J., Platt, U., and Burrows, J. P.: Lightweight diode laser spectrometer CHILD (Compact High-altitude In-situ Laser Diode) for balloonborne measurements of water vapor and methane, Appl. Optics, 44, 91-102, 2005.

Harries, J. E., Russell, J. M. I., Tuck, A. F., Gordley, L. L., Purcell, P., Stone, K., Bevilacqua, R. M., Nedoluha, G., and Traub, W. A.: Validation of measurements of water vapor from the Halogen Occultation Experiment (HALOE), J. Geophys. Res., 101, 10205-10216, doi:10.1029/95JD02933, 1996.

Hoogen, R., Rozanov, V. V., and Burrows, J. P.: Ozone profiles from GOME satellite data: Algorithm description and first validation, J. Geophys. Res., 104, 8263-8280, 1999. 
Kirk-Davidoff, D. B. and Lamarque, J.-F.: Maintenance of polar stratospheric clouds in a moist stratosphere, Clim. Past, 4, 6978, doi:10.5194/cp-4-69-2008, 2008.

Kirk-Davidoff, D. B., Hintsa, E. J., Anderson, J. G., and Keith, D. W.: The effect of climate change on ozone depletion through changes in stratospheric water vapour, Nature, 402, 399-401, 1999.

Kley, D., Russell III, J. M., and Phillips, C. (Eds.): SPARC assessment upper tropospheric and stratospheric water vapour, WCRPNo. 113, WMO/TD-No. 1043, SPARC Report No. 2, WCRP, Geneva, Switzerland, 2000.

Kratz, D. P., Chou, M.-D., Yan, M. M.-H., and Ho, C.-H.: Minor trace gas radiative forcing calculations using the $\mathrm{k}$ distribution method with one-parameter scaling, J. Geophys. Res., 103, 31647-31656, doi:10.1029/1998JD200009, 1998.

Lahoz, W. A., Carr, E. S., Froidevaux, L., Harwood, R. S., Kumer, J. B., Mergenthaler, J. L., Peckham, G. E., Read, W. G., Ricaud, P. D., Roche, A. E., and Waters, J. W.: Northern hemisphere mid - stratosphere vortex processes diagnosed from $\mathrm{H}_{2} \mathrm{O}$, $\mathrm{N}_{2} \mathrm{O}$, and potential vorticity, Geophys. Res. Lett., 20, 26712674, doi:10.1029/93GL02475, 1993.

Lahoz, W. A., O’Neill, A., Heaps, A., Pope, V. D., Swinbank, R., Harwood, R. S., Froidevaux, L., Read, W. G., Waters, J. W., and Peckham, G. E.: Vortex dynamics and the evolution of water vapour in the stratosphere of the southern hemisphere, Q. J. Roy. Meteorol. Soc., 122, 423-450, doi:10.1002/qj.49712253007, 1996.

Lambert, A., Read, W. G., Livesey, N. J., Santee, M. L., Manney, G. L., Froidevaux, L., Wu, D. L., Schwartz, M. J., Pumphrey, H. C., Jimenez, C., Nedoluha, G. E., Cofield, R. E., Cuddy, D. T., Daffer, W. H., Drouin, B. J., Fuller, R. A., Jarnot, R. F., Knosp, B. W., Pickett, H. M., Perun, V. S., Snyder, W. V., Stek, P. C., Thurstans, R. P., Wagner, P. A., Waters, J. W., Jucks, K. W., Toon, G. C., Stachnik, R. A., Bernath, P. F., Boone, C. D., Walker, K. A., Urban, J., and Murtagh, D.: Validation of the Aura Microwave Limb Sounder middle atmosphere water vapor and nitrous oxide measurements, J. Geophys. Res., 112, 1-24, 2007.

Li, J. and Barker, H. W.: A Radiation Algorithm with Correlatedk Distribution, Part I: Local Thermal Equilibrium, Physics, 62, 286-309, doi:10.1175/JAS-3396.1, 2004.

Livesey, N. J., Synder, W. V., Read, W. G., and Wagner, P. A.: Retrieval algorithms for the EOS 10 Microwave Limb Sounder (MLS), IEEE T. Geosci. Remote, 44, 1144-1155, 2006.

Michelsen, H. A., Irion, F. W., Manney, G. L., Toon, G. C., and Gunson, M. R.: Features and trends in Atmospheric Trace Molecule Spectroscopy (ATMOS) version 3 stratospheric water vapor and methane measurements, J. Geophys. Res., 105, 22713-22724, doi:10.1029/2000JD900336,2000.

NASA: US Standard Atmosphere Supplements, US Government Printing Office, Washington, D.C., 1976.

Pan, L. L., Randel, W. J., Massie, S. T., Kanzawa, H., Sasano, Y., Nakajima, H., Yokota, T., and Sugita, T.: Variability of polar stratospheric water vapor observed by ILAS, J. Geophys. Res., 107, 8214, doi:10.1029/2001JD001164, 2002.

Pan, L. L., Bowman, K. P., Shapiro, M., Randel, W. J., Gao, R. S., Campos, T., Davis, C., Schauffler, S., Ridley, B. A., Wei, J. C., and Barnet, C.: Chemical behavior of the tropopause observed during the Stratosphere-Troposphere Analyses of Regional Transport experiment, J. Geophys. Res., 112-124,
doi:10.1029/2007JD008645, 2007.

Peter, T.: Microphysics and heterogeneous chemistry of polar stratospheric clouds, Annu. Rev. Phys. Chem., 48, 785-822, 1997.

Rodgers, C. D.: Inverse Methods for Atmospheric Sounding: Theory and Practice, World Scientific, Singapore, 2000.

Rothman, L., Gordon, I., Barbe, A., Benner, D. C., Bernath, P., Birk, M., Brown, L., Campargue, A., Champion, J.-P., Chance, K., Coudert, L., Dana, V., Devi, V., Fally, S., Flaud, J.-M., Gamache, R., Goldman, A., Jacquemart, D., Kleiner, I., Lacome, N., Lafferty, W., Mandin, J., Massie, S., Mikhailenko, S., Miller, C., Moazzen-Ahmadi, N., Naumenko, O., Nikitin, A., Orphal, J., Perevalov, V., Perrin, A., Predoi-Cross, A., Rinsland, C., Rotger, M., Simeckova, M., Smith, M., Sung, K., Tashkun, S., Tennyson, J., Toth, R., Vandaele, A., and Vander Auwera, J.: The HITRAN 2008 molecular spectroscopic database, J. Quant. Spectr. Ra., 110, 533-572, doi:10.1016/j.jqsrt.2009.02.013, 2009.

Rozanov, A.: Modelling of the radiative transfer through a spherical planetary atmosphere: application to the atmospheric trace gas retrieval from occultation and limb measurements in UV-VisNIR, Ph.D. thesis, Universität Bremen, 2001.

Rozanov, A., Rozanov, V., Buchwitz, M., Kokhanovsky, A., and Burrows, J. P.: SCIATRAN 2.0 - A new radiative transfer model for geophysical applications in the $175-2400 \mathrm{~nm}$ spectral region, Adv. Space Res., 36, 1015-1019, doi:10.1016/S02731177(02)00095-9, 2005.

Rozanov, A., Weigel, K., Bovensmann, H., Dhomse, S., Eichmann, K.-U., Kivi, R., Rozanov, V., Vömel, H., Weber, M., and Burrows, J. P.: Retrieval of water vapor vertical distributions in the upper troposphere and the lower stratosphere from SCIAMACHY limb measurements, Atmos. Meas. Tech., 4, 933-954, doi:10.5194/amt-4-933-2011, 2011.

Rozanov, A. V., Rozanov, V. V., and Burrows, P. J.: Combined differential-integral approach for the radiation field computation in a spherical shell atmosphere: Nonlimb geometry, J. Geophys. Res., 105, 22937-22942, doi:10.1029/2000JD900378, 2000.

Rozanov, V. V., Diebel, D., Spurr, R. J. D., and Burrows, J. P.: GOMETRAN: A radiative transfer model for the satellite project GOME, the plane-parallel version, J. Geophys. Res., 102, 16683-16695, doi:10.1029/96JD01535, 1997.

Russell, J. M. I., Tuck, A. F., Gordley, L. L., Park, J. H., Drayson, S. R., Harries, J. E., Cicerone, R. J., and Crutzen, P. J.: HALOE Antarctic observations in the spring of 1991, Geophys. Res. Lett., 20, 719-722, doi:10.1029/93GL00497, 1993a.

Russell, J. M. I., Gordley, L. L., Park, J. H., Drayson, S. R., Hesketh, W. D., Cicerone, R. J., Tuck, A. F., Frederick, J. E., Harries, J. E., and Crutzen, P. J.: The Halogen Occultation Experiment, J. Geophys. Res., 98, 10777-10797, doi:10.1029/93JD00799, 1993b.

Schoeberl, M., Douglass, A., Hilsenrath, E., Bhartia, P., Beer, R., Waters, J., Gunson, M., Froidevaux, L., Gille, J., Barnett, J., Levelt, P., and DeCola, P.: Overview of the EOS aura mission, Geosci. Remote Sens., 44, 1066-1074, doi:10.1109/TGRS.2005.861950, 2006.

Solomon, S., Rosenlof, K. H., Portmann, R. W., Daniel, S. M. D., Sanford, T. J., and Plattner, G. K.: Contributions of Stratospheric Water Vapor to Decadal Changes in the Rate of Global Warming, Science, 327, 1219-1223, doi:10.1126/science.1182488, 2010. 
Stiller, G. P., Kiefer, M., Eckert, E., von Clarmann, T., Kellmann, S., García-Comas, M., Funke, B., Leblanc, T., Fetzer, E., Froidevaux, L., Gomez, M., Hall, E., Hurst, D., Jordan, A., Kämpfer, N., Lambert, A., McDermid, I. S., McGee, T., Miloshevich, L., Nedoluha, G., Read, W., Schneider, M., Schwartz, M., Straub, C., Toon, G., Twigg, L. W., Walker, K., and Whiteman, D. N.: Validation of MIPAS IMK/IAA temperature, water vapor, and ozone profiles with MOHAVE-2009 campaign measurements, Atmos. Meas. Tech., 5, 289-320, doi:10.5194/amt-5-289-2012, 2012.

Tikhonov, A. N.: On the solution of incorrectly stated problems and a method of regularization, 151, Dokl. Acad. Nauk, SSSR, 501$504,, 1963$.

Tikhonov, A. N. and Arsenin, V. Y.: Solutions of ill-Posed Problems, Wiley, New York, 1977.

von Clarmann, T., Höpfner, M., Kellmann, S., Linden, A., Chauhan, S., Funke, B., Grabowski, U., Glatthor, N., Kiefer, M., Schieferdecker, T., Stiller, G. P., and Versick, S.: Retrieval of temperature, $\mathrm{H}_{2} \mathrm{O}, \mathrm{O}_{3}, \mathrm{HNO}_{3}, \mathrm{CH}_{4}, \mathrm{~N}_{2} \mathrm{O}, \mathrm{ClONO}_{2}$ and $\mathrm{ClO}$ from MIPAS reduced resolution nominal mode limb emission measurements, Atmos. Meas. Tech., 2, 159-175, doi:10.5194/amt-2-159-2009, 2009. von Savigny, C., Ulasi, E. P., Eichmann, K.-U., Bovensmann, H., and Burrows, J. P.: Detection and mapping of polar stratospheric clouds using limb scattering observations, Atmos. Chem. Phys., 5, 3071-3079, doi:10.5194/acp-5-3071-2005, 2005.

Waters, J. W., Froidevaux, L., Harwood, R. S., Jarnot, R. F., Pickett, H. M., Read, W. G., Siegel, P. H., Cofield, R. E., Filipiak, M. J., Flower, D. A., Holden, J. R., Lau, G. K., Livesey, N. J., Manney, G. L., Pumphrey, H. C., Santee, M. L., Wu, D. L., Cuddy, D. T., Lay, R. R., Loo, M. S., Perun, V. S., Schwartz, M. J., Stek, P. C., Thurstans, R. P., Boyles, M. A., Chandra, K. M., Chavez, M. C., Chen, G. S., Chudasama, M. V., Dodge, R., Fuller, R. A., Girard, M. A., Jiang, J. J., Jiang, Y., Knosp, B. W., LaBelle, R. C., Lam, J. C., Lee, K. A., Miller, D., Oswlad, J. E., Patel, N. C., Pukala, D. M., Quintero, O., Scaff, D. M., Van Synder, W., Tope, M. C., Wagner, P. A., and Walch, M. J.: The Earth Observing System Microwave Limb Sounder (EOS MLS) on the Aura satellite, IEEE T. Geosci. Remote, 44, 1075-1092, 2006.

Wiscombe, W. J. and Evans, J. W.: Exponential-sum fitting of raditaitve transmission functions, J. Comput. Phys., 24, 416-444, 1977. 